\title{
Transforming Public Service Performance in West Africa Through Innovations: EXPERIENCES FROM GHANA AND NIGERIA
}

AWOSIKA, Felix Olanrewaju

\section{Abstract}

Dublic service reflects the state of the advance beyond its public service. The need for innovation in the public service therefore cannot be underestimated. It is at the heart of the public service's efforts to improve performance and productivity. It is important to note that the logic of public service performance is changing profoundly due to innovations. This development paves the way for new forms of interaction and socio-economic composition in social and economic life. This article provides an overview of the on-going service transformation and applies it to public service delivery in West Africa. Our focus is on innovation in public service delivery, which refers to innovations that aim at renewing or improving public service performance. Using secondary data and content analysis, this article examines the phenomenon of low performance in the public service in two West African countries and recommends measures for improvement. The article concludes that innovations in the public sector guarantee survival and improve performance in public service delivery.

Keywords: Public Service, Performance, Innovations, Reforms, Bureaucracy, New Public Management, Ghana, Nigeria 
Transforming Public Service Performance in West Africa through Innovations 73

\section{Introduction}

In most countries of the world, the need for innovation in public service delivery has long been stressed. Changes in global markets, increased customer expectations, need for new technologies and processes, improving existing products and services, and government pressure, have all led to innovation which is becoming a key focus in the public sector (Obianyo, 2010:21). Today, public service organisations are often under as much pressure to cut costs, reduce waste and improve efficiency as private sector ones. Indeed, there is a historic tendency for costs in the public sector to rise faster than those in the rest of the economy (Mulgan and Albury, 2003:8). This stems primarily from the general lack of competition. Here, innovation is seen to be a mechanism which will stimulate a more commercial orientation within public services. As a result, innovation has become the gateway and engine to growth, economic transformation, and decrease in poverty. Innovation is actually the engine of economic growth. It deals with governance, political issues and human problem which are very difficult to solve (Okibo and Shikanda, 2013:67; Arfeen and Khan, 2012:9).

Public administration scholars and experts have argued that 'innovation' in the public sector is a powerful engine and a key instrument for the reform and revitalization of both fully state-owned bodies and quasi-governmental organizations and agencies (Eran, Aviv; Nitza and Ayalla, 2008:307). Without innovation capability, there would be no computers, aeroplanes, high-tech television, and wireless technology, just to name a few. This shows that innovation has been practiced throughout human history and has become a way of improving human life. Lack of innovation or innovative ideas hinder the performance of the public service and other sectors of the economy by inefficient utilization of resources. Costs, time and quality standards are most times not achieved due to lack of creativity and innovation.

Despite the importance of innovation in rendering effective, required and adequate services to the citizenry, it has been observed that innovation in the public service in Africa in general and West Africa countries in particular has suffered from not only the lack of research seeking to understand it, but also a considerable lack of recognition of its importance, contrary to the case in developed societies. Blayse and Manleyi (2004:8) observed that in most developing countries, there is a perception that public sector is not generally innovative and that there is much room for improvement. It is therefore evident that the clamour for innovation and innovative incentives in the public service is 
not just for competitiveness, improved productivity or technology, or enhancing the living standards, also the issue of effective service delivery seems to be top on agenda for the recent clamour for innovation. Even most countries have enforced this through various reform programmes. It is important to note that innovation has been seen only as a supplement to the main role and activities to the government. Hence, it is difficult to find innovative individuals and organizations in the public sector in these countries as compared to developed countries. This article therefore takes a cursory look at public sector performance and the extent to which innovation in public service delivery has impacted on public service performance in West Africa with particular reference to Nigeria and Ghana.

\section{Methodology}

This article aims at exploring and explaining the causes of low public sector performance in West Africa and how it can be improved. Based on this, the study is situated within the qualitative paradigm of social research which is deemed appropriate for exploratory and explanatory studies (Babie, 2004). This study used secondary sources of data while the design for this paper is the content analysis design. This was used to analyze written reports, journal articles, and other relevant sources of data about the topic. It reviews the literature on public service globally, in Africa and two countries in West Africa, i.e., Nigeria and Ghana, to enable us analyze the trends, processes, dynamics, and major innovations in their public services. The choice of the two countries is instructive because of the strategic place/role of the countries in West Africa. Also these countries have undertaken substantial reform efforts and show the symptoms of trends, processes, dynamics and innovations in public service delivery in West Africa.

\section{Concept of Innovation}

The word "innovation" seems to be a contemporary popular buzzword used loosely by politicians, policymakers and others in relation to 'improving' or making the 'public sector' more effective and efficient. Governments around the world advance innovation as a significant means to improve public services (Walker, 2006:311). The concept of innovation has developed mainly around private business, with an historic focus on product innovation. Innovation in services is more difficult to define and identify, 
Transforming Public Service Performance in West Africa through Innovations 75

particularly innovation in public services. The inevitability of innovation is informed by a dire need for organizations to survive and grow. As a concept, it entails the introduction of new ideas that would enhance achievement of organizational purposes thereby ensuring growth in the organization (Maduabum, 2014:13).

Innovation is 'an idea, practice, or object that is perceived as new by an individual or another unit of adoption' (Rogers, 1983:11). In his study concerning the investigation of why local authorities in England innovate and to what purpose, Newman (2001:61) define innovation as, "discontinuous or step change, as something which was completely new to a particular local authority (though which may have previously been applied elsewhere), and a change which had already been implemented rather than just an aspiration or planned initiative." This definition emphasises already implemented sporadic incremental changes concerning new innovations to the local authority in question with particular focus on implementation. In the view of Slaughter (1998:35), innovation is the actual use of a nontrivial change and improvement in a process product or system that is novel to the institution developing it.

The Oslo Manual (OECD/Eurostat 2005:3) defines innovation as "the implementation of a new or significantly improved product (good or service) or process, a new marketing method, or a new organisational method in business practices, workplace organisation or external relations." This definition sees innovation as the successful introduction of something new and useful. In this definition, the notions of "new" and "useful" should be interpreted as context-specific, organisation specific, rather than universal or marketwide. To Lundvall (1992) and Mytelka (2000), innovation is the result of a complex interaction between various actors and institutions. Based on the above definitions, we can therefore argue that innovation involves the act of researching, acquiring, introducing and building up new ideas, technology, processes and products aimed at not just for solving problems, but improving efficiency and effectiveness, and thus enhancing the standard of living. That is to say that innovation must not just look only at improving an organization competitiveness in the commercial world but should also seek to enhance living standards.

The use of the term 'innovation' in the public sector context encompasses a range of interpretations, such as improvement, modernisation, reform, etc. However, the level of 'sophistication' of such innovation varies enormously between countries, ranging from relatively simplistic, yet nonetheless effective, procedural changes to administrative 
practice, through to more complex reforms and modifications, often involving dramatic changes to working practices and the utilisation of advanced technological solutions (Cunningham \& Karakasidou, 2009:8). Innovation in the public sector is a new and/or significantly improved product, service or process within the responsibility of a public organisation - national or regional, delivered with or without the involvement of the private sector (and hence including public private partnerships). This could include efforts and mechanisms to improve the uptake and flow of innovative practices throughout public sector organisations. Innovation in the public service refers to conceiving a creative idea and successfully implementing it to solve a pressing public service problem. It is an effective, creative and unique answer to new problems or a new answer to old problems. Innovation in the public service can be in human resource development and management, service delivery, information and communications technologies, policies, structures, procedures, processes, or even in products. It is important to note that innovation in the public sector does not always result in new public services, but may be linked to institutional renewal, new forms of governance, process innovation, digitization and/or organizational improvements (e.g. changes in management techniques, the introduction of performance management or strategic planning), etc (Cunningham \& Karakasidou, 2009:1).

Public sector innovation is about new ideas that work at creating public value. The ideas have to be at least in part new (rather than improvements); they have to be taken up (rather than just being good ideas); and they have to be useful." In terms of measurement, a criterion that an innovation is "useful" requires that enough time has elapsed that an assessment of impact can be made. Hence, this is problematic for measurement of recent innovations (Mulgan, 2007). Cunningham and Karakasidou (2009:5), distinguishes two aspects of innovation in the public sector. These include: stimulating knowledge and innovation for realising societal goals and solving societal problems; and stimulating innovation for improving the process of public service provision. Thus, the government uses of a broader notion of innovation when applied in the public sector context. 
Transforming Public Service Performance in West Africa through Innovations 77

\section{Why Innovation in Public Sector Management}

The need for innovation in the public service cannot be underestimated. Innovation needs to be at the heart of the public service's efforts to improve performance and productivity and develop new capabilities, business and markets, and also contribute to enhancing the standard of living as well as creating new opportunities. No wonder, Maron (2008) warned that should the public service fail to be innovative, there is a risk that it either will lag behind in the international perspective or that it will be ineffective in service delivery to the populace. The higher the levels of innovation in the public service the greater the likelihood that it will increase its contribution to the welfare of the citizens. Innovation in the public sector is now recognised as a vital factor in meeting the challenges of globalisation and demographic changes, while at the same time, sustaining a high level of services to citizens and businesses (Donahue, 2005; Bloch; Bugge and Sliperseater, 2010:1). Innovation has the potential of opening new doors, reformulating old problems, breaking with policy deadlocks, bringing new actors together and formulating and implementing new ideas (Sørensen and Torfing, 2012:3).

Public service innovations initiative provides a number of opportunities to improve governance. Proponents of public service innovations have suggested many benefits that will result directly or indirectly from such projects. These include; efficiency which can reduce errors and improve consistency of customers (Seifert, 2003:8). Innovations advocates like Heek (2002), Hernon and McClure (1988) are of the opinion that by reducing the amount of time spent on traditional mode of operations, innovations will give government workers an opportunity to develop new skills and advance their careers (Breen, 2000:54). Also, innovation is crucial for effective public service management in a dynamic society (Hartley 2005:30). As noted by Albury (2005:53) it is only through a process of innovation that public services can shift out of a $20^{\text {th }}$ century 'mass provision' mode to a more personalised mode. Without innovations in the areas of staffing, organisation and delivery, service agencies will not be able to adapt to these changed demands. Innovation is therefore seen to be a mechanism which will stimulate a more commercial orientation within public services. In particular, government increasingly focuses on the skills required amongst public servants in order to build the capacity and ability to administer and deliver those core state functions which are less amenable to being provided by purely private actors (Kamarck, 2003:13). Maduabum (2014:11) 
however noted that application of innovative ideas is inevitable for an organization that is desirous of survival and growth.

It is important to note that innovation is essential in public services, both to deliver the 'more for less' agenda and to offer radical alternative approaches to major social and economic issues. Balancing the needs of multiple stakeholders, rising expectations for service range and quality, the potential of new technology and the rising cost of delivering public services is forcing innovation on top of the agenda across all departments (IDeA Knowledge, 2005). In the words of Damanpour \& Gopalakrishnan (1998:53); Hargadon and Sutton (2000:32), innovation is considered essential to effective public sector management in the following ways:

- reducing costs and increasing productivity, thereby improving profits and strengthening the organisation;

- maintaining competitiveness in a globalised economy;

- the organisation's ability to adapt to changing environments (which may be legislative, technological, social, economic, and physical);

- breathing new life into slowing or stagnant markets or other operational areas, alternatively facilitating entry into new markets;

- inculcating an organisational culture of creativity: particularly visible in research oriented organisations or those working in dynamic markets like ICT, but also relevant to any organisation which seeks to attract high quality creative staff and managers at any level.

Due to the importance of innovations in improving and transforming the performance and productivity in the public sector, it is paramount that public sector improves and innovates along with the rest of society. In their own views, Markus; Johan; Carter, and Stig (nd:19) stated that innovation is important in the public sector because of the following:

- First, there are economic motivations for stimulating a cost-effective and productive administration and management of the civil service, such as financial management, health services, collection of taxes and educational offer. 
Transforming Public Service Performance in West Africa through Innovations 79

- Secondly, many activities in the public sector will be devoted to affect the innovative performance of the private sector or in other parts of the public sector. It is also argued that an innovative public sector is important to innovation in the private sector, due to the close interactions between the private and the public sector in many domains, and due to the role of the public sector as a facilitator of infrastructure for the private sector.

- Thirdly, the efficiency of a country's public sector and a delivery of public services of good quality are vital to achieve transparent operations, which may improve the understanding and legitimacy of how the public sector works. A modern and effective public sector with increased accountability to the public may result in public satisfaction with the services offered, which may improve the trust of the public sector (Eran, et al. 2008:312).

- Fourth, innovation in the public sector may be motivated by political reasons. The public sector does not as a whole face the test of competitive markets, but politicians and political parties in Western democracies face the test of competitive electoral politics. Political support and votes are gained through being seen to perform better than opposing political actors, and the provision, delivery, and cost of public services is an important domain for competition between claims of effective (potential) performance.

- Lastly, innovation in the public sector may also be motivated by personal reasons. Public sector policy makers, managers and professional workers may gain personal satisfaction, motivation and status among their professional community and society at large from improving public services and the users experience with these. As such by proposing innovations they may boost their own careers.

\section{Public Service in Nigeria and Ghana: A Brief Overview}

Public service reflects the state of the nation and no nation has been able to advance beyond its public service. The public service is fundamental to good governance. It is an integral part of democracy because it serves as the neutral administrative structure, which carries out the decisions of elected representatives of the people. The public 
service is seen as the backbone of every other sector of any nation's economy. This is because public service is the highest employer of labour and is in strategic position to provide essential services to the citizens (Fatile and Adejuwon, 2010:181). In this section therefore, attempts were made to give a synopsis of public service in Nigeria and Ghana.

\section{The Nigerian Civil Service}

The Nigerian civil service evolved from the colonial service which was established by the British authorities as the administrative machinery of the country (Economic Commission for Africa, 2010:63). That is, the public service in Nigeria is a child of British colonial administration and like its parent, it is elitist (Oyediran, 2007:68). The civil service in Nigeria has been succinctly articulated as an instrument of governance that places before the leadership an assured quality of experience and competence which serves as the protector or the line between partisan and national interest (Ahmed, 2005:38). As a result, efforts are always made to make the service perform better since the civil service is about people and service.

During the 1950s and 1960s, the Nigerian civil service was regarded as one of the best in the Commonwealth, and up till the mid 1980s. Unfortunately from the mid 1980s, the Nigerian civil service was far from being ideal. The Nigerian public service is strategically located in roles, functions, activities, resources and services that their performance determines the state and level of development. Yet the service has been riddled with inefficiency, ineffectiveness, mismanagement, shoddiness, inertia, routine, poor responsiveness, conflicts, corruption, sectionalism, incompetence, and low productivity. The service has not had the shills, techniques, values, orientations, drive and awareness that would direct and enable it to manage efficiently and effectively their enormous task and responsibilities. The problem of Nigerian civil service is traceable to the lack of consciousness, non-application of modern techniques of management, the absence of performance emphasis, the absence of systematic evaluation, the lack of emphasis on accountability and responsibility (Ikelegbe, 2005:16; Uhunmwuangho and Osemeke, 2010:26). The Nigerian civil service was tradition-bound, somewhat ponderous and showing signs of deterioration and several undesirable characteristics of which the following were the most prominent: over-centralisation, incessant conflict between cadres, little emphasis on results and concrete performance, counter-productive, 
separation of authority from responsibility at the topmost hierarchy, dangerously low staff morale and productivity, inadequate staff development practices. Indeed at that point in time the civil service was displaying a patent inability to cope effectively with the challenges of a modern complex and development hungry society (Adegoroye, 2006:7).

Public service in Nigeria has been characterized by poor performance and productivity. It is been criticized for being one of the slowest to integrate technological advancement. Okafor (2005:67), traces poor performance of the Nigerian bureaucracy to the following:

- bureaucratic inflexibility and rigidity inherited from colonial administration;

- quick Africanisation of the civil service in which inexperienced and less qualified native officials were recruited into various job positions;

- the desire of early politicians for complete nationalisation of the public bureaucracy to fulfil campaign promises and to solve unemployment problems; recruitments based on political, family, ethnic and religious considerations;

- inadequate office space and other administrative infrastructure at independence;

- over-staffing and poor remunerations which encouraged corruption and moonlighting

The Nigerian public service is however, large and does contribute largely to the economic growth of the nation, but most elements especially of technology that make up the development process are not adequately provided. As argued by Okafor (2005:670, each of the stated problems above plays its roles in diminishing the administrative capacity in public bureaucracy. It is important therefore to note that the performance of the public service in Nigeria has remained very dismal, inefficient and ineffective. The search for a more responsive and effective public service led to the setting up of different commissions at various periods. In sum, public service reform in Nigeria has sought to improve the performance of the administrative system through managerial reforms. 


\section{The Ghanaian Civil Service}

The Ghanaian civil service was once regarded as the "finest, most relevant and performance-oriented institutions in Africa." At the time, it was well trained, adequately remunerated and resourced while its size was manageable and security of tenure as well as anonymity and neutrality of the civil servants were guaranteed. All these factors combined to produce an environment which was congenial and thus elicited in most civil servants the highest degree of performance and productivity. However, these good days turned into bad times under which the civil service was described as a "moribund, paperpushing institution" (Nti, 1978:1 cited in Economic Commission for Africa, 2010:50).

In recent times, the productivity of Ghana's public sector has become a concern to scholars and public servants alike. There have been numerous calls on the public sector to increase its productivity to enhance quality service delivery and to get value for money. These calls can be understood in the light of the fact that the performance of the public sector has implications for economic development for the country. The relevance of public sector productivity has necessitated an avalanche of attempts to reform the public sector in Ghana with the aim of enhancing efficiency, effectiveness, and the quality of public service (Sakyi, 2008:72). As a result, there have been calls on public sector workers to increase productivity in the public sector of Ghana. This comes against the backdrop that productivity in Ghana's public sector appears to be consistently declining. While this seems to be the situation, it appears there is paucity of literature on the actual causes of productivity and how it can be improved in Ghana (Kwame, Alex and Emmanuel, 2013:22).

Ghana's civil service reform efforts have produced disappointing results (World Bank 2008; Owusu, 2006:701). As noted by ECA (2010:51), the features of Ghana's civil service have been identified as debilitating to its performance includes:

- $\quad$ substantial overstaffing, especially at junior levels - lack of manpower planning;

- deterioration of real salaries/wages plus a high degree of wage compression;

- lack of morale/motivation - incentives problems;

- inability of major institutions involved in civil service management to provide policy guidance, direction, and supervision to sectoral/departmental units defective managerial competence; 
- over-centralization and over-concentration of powers and functions at the national level;

- $\quad$ poor physical work environment and poor facilities - logistical problems;

- excessive bureaucratization and red tape (e.g., of promotions and appointments to key posts);

- lack of political direction and commitment, leading to apathy and inertia; and

- $\quad$ serious deficiencies in training institutions and programmes (ECA, 2010:51).

In Ghana for instance, it is very wearisome seeking the supply of water and electricity for domestic or industrial use. Consumers have to go through numerous bureaucratic channels before approval is given and in most cases, corrupt officials demand facilitation fees to hasten processes. Passport acquisition, registration of lands, law enforcement and judicial processes, health services, investment promotion, business registration, salary and pension processes have all been couched in cumbersome procedures that leave clients frustrated in their quest for services. In some cases, consumers abandon pursuit of these services in midstream, due to delays and other forms of bureaucratic insensitivities.

\section{Bureaupathology and Public Service Performance in West Africa: Nigeria and Ghana in Focus}

Bureaucracy and Innovation are inextricably linked, in that organizations that are desirous of survival and growth particularly in a turbulent environment requires the application of both concepts (Maduabum, 2014:11). For instance, whereas bureaucracy introduces specialization, structure, rules and regulations, predictability, rationality and partial democracy amongst others, innovation brings about positive changes that quite often assist in surmounting impediments in the quest for growth. In practice however, reverse sometimes appears to be the case.

The essence of bureaucracy is to enable large organisations to be managed, to achieve efficiency and be more accountable to the people. In other words, bureaucracy is the coordination of organisational activities for effective, efficient and economical provision of services by public and private organisations. Max Weber refers to bureaucracy as the ideal and rational type of administration useful for achievement of 
positive results. He however notes the dysfunctions of bureaucracy due to excessive application of its guiding principles by office holders. Indeed excessive bureaucracy negatively impacts on social and economic development especially in poor countries. The underlying assumption of Weber's model is that authority which provides legitimacy to an organisation system is legal rational rather than traditional or charismatic. Hicks and Gullet (1976:144) x-rayed the ills of bureaucracy as they affect formal organizations as possible causes of inability of superior officers to appreciate contributions made by their subordinates especially where such contributions are seen as innovative and hence do not strictly accord with role-expectations of the subordinates.

The bottlenecks associated with service delivery have made bureaucracy very unpopular to the people, because excessive bureaucracy inhibits productivity and contributes to loss of large revenues to the government. Bureaucracy has many unintended consequences or dysfunctions. It is a "machine model" that is non adaptive and impersonal. Its rigidity, leads to its failure to account adequately for many important human characteristics. It offers numerous opportunities for members to displace objectives and to work for personal or sub-unit goals which may not contribute adequately to the achievement of overall objectives of the organization. Innovative ideas are seen by bureaucratic officials as disturbances to an otherwise ordered situation. Such ideas are therefore never seen as a necessary life-giving element to an evolving, adaptive organization (Maduabum, 2014:310). In order to survive the challenges posed in a highly competitive environment, many businesses, especially private organisations have shifted focus and are de-bureaucratising their administrative processes for better service delivery. According to Sarji, (1996), the primacy of the customer of public service dictates that the Civil Service provides services that are responsive to the needs of its primary customer and the public. The standards of service should be stipulated in line with customer expectations for efficient, fast and friendly services. Consumer concerns are for reliability, credibility, accessibility and timelines in service delivery. For any country to develop, it is very imperative for its government to provide goods and services that the private sector does not usually venture into, especially water, sanitation, waste disposal, road, health, housing, education, electricity, etc. These services, according to World Bank Report (1999), are usually those that the private sector does not want to provide or those that people cannot afford the price at the given market value (Oyelaran-Oyeyinka, 2006). This prompted Thompson (1961:152-177), to referred to the ills of the 
bureaucratic organisation as 'Bureaupathology', a disease of bureaucracy which he further suggested are those dysfunctions which are produced by "bureaupathic behaviour'.

Bureaupathology according to Peter (1997:104) is negative administrative behaviours of professionals and experts in organisation which thwart achievement of public goals and delivery of quality public service to consumers. Modibo (1978) says these are administrative pathologies by which public servants, while misconceiving their powers, functions and responsibilities, act ultra vires, in bad faith, out of malice or even with illmotives, thereby exhorting image, tips, importance and cash benefits from service consumers. He describes bureaupathology as phenomena by which public servants use their statuses, positions and authority to carnally procure for themselves some benefits from investors, contractors, consultants and suppliers. Peter (1997:204) calls bureaupathology the administrative evils in public service delivery, because it is arbitrary due to the use of discretionary power, violate economic, social and political rights of consumers of public service; it sabotage government socio-economic and political programmes to the disadvantage of constituents; they delay services delivery to strategic investors and other consumers; and, is associated with ritualism and self-egoism of professional and experts. While Modibo (1978) argues that bureaupathology is associated with: bureaucratic insensitivity; misuse of administrative power and discretion; lack of concern for customer's plights; lack of customer focus; and misuse of monopoly in service delivery.

In Nigeria, bureaucracy has significant influence on the dysfunctionality of public service. This dysfunctional characteristic of bureaucracy vis-à-vis implementation of innovative ideas clearly manifest in the Nigerian situation. As a result, the public service is characterised by a spirit of animosity and jealousy rather than of cooperation and team work. This spirit of animosity exists between peers as well as between superiors and subordinates. In fact, the animosity and jealousy become very high when a subordinate is perceived by his superior officer as being innovative and may supersede him. The superior officers employ the same bureaucracy as a means of scuttling the application of innovative ideas especially where such ideas emanate from their subordinates (Maduabum, 2014:11;16). In addition, Ekpo (1979:8) observes that the Nigerian bureaucracies are corrupt, inefficient and overstaffed. Complementing this is the Udoji Report of 1974 which charged the bureaucracies with nepotism, ethnic loyalties, 
corruption, elitism, inability of superiors to delegate responsibilities, unreliability of junior staff in executing delegated tasks, failure of all to apply specialized knowledge and training skills in the management of the public service, and failure to appreciate the importance of timeliness or efficiency in the performance of tasks. The report concluded by saying that the entire Nigerian bureaucracy was not results-oriented. Too bad it seems. In pursuit of private goals, several officials in the Nigerian bureaucracies form cliques and informal groups in order to maximize their benefits: all at the expense of the attainment of institutional goals. In effect, bureaucracies which are corrupt and steadily suffer goal displacement can hardly be expected to be efficient. If the bureaucracies are efficient at all in any way, it is in the special role of protecting its class interests rather than serving the masses whose interests it was created to serve (Eme and Emeh, 2012:30).

Nigeria's history has been marked by a crisis of governance. The consensus arising out of the general debates on good governance and its requirements have severely scored the bureaucracy for its failure to provide the much needed institutional support for good governance. It is the abiding concern of this paper to discharge the bureaucracy from the "dock" where it sadly stands; to establish that the political superstructure is largely to blame for the leadership failure; and to argue that due to obvious constraints, the public service failed to optimize its statutory role of translating the will of the state into concrete and desirable terms (Ozohu-Suleiman, 2010).

Looking at bureaucracy in contemporary public service in Ghana, Adu-Gyamfi (2005) criticises Weber's concept of bureaucracy as being responsible for the following:

- lack of initiative, creativity and innovation in public service delivery in organisations such as Ghana Education Service, Town and County Planning Department, Department of Birth and Death Registry, Land Title Registry and the Controller and Accountant-General's Department due to excessive adherence to laid down rules, regulations, procedures and methods;

- emergence of espirit de corps, self-egoism and ritualism instead of team work;

- delays in service delivery to customers by public agencies such as Customs, Excise and Preventive Service, the Registrar-General's Department, Ghana Investments Promotions Centre, etc; 
- centralisation of strategic investment services by top public officers;

- $\quad$ rigidity and inflexibility of middle class public servants leading to exploitation of the consumer in service delivery.

It is therefore instructive to note that the civil service systems of African countries inherited from the colonial rulers in the 1960s were inspired by the Weberian bureaucratic model (Adamolekun 2002:379). In Africa, the civil service structures which were based on the bureaucratic model led to inefficient organizations, excessive red tape and structural arrangements that impeded as much or more than serve the implementation of public policy. It discouraged individual initiative and supported a culture of unreflective defence of the status quo. This therefore provides an understanding of the challenges that Africa has to overcome to truly become innovative public services.

\section{New Public Management and Public Sector Innovations: Redemptive Attempts and Pitfalls}

Since the advent of New Public Management (NPM), public service innovations have become increasingly popular around the world as a strategy for improving governance and scaling up service quality. The New Public Management philosophy is part of the tendency towards privatization of the public sector and has transformed its role in many sectors and countries. The replacement of the term 'citizens' with the term 'customers' to describe the users of public services exemplifies this movement towards characterizing the public sector in terms of market mechanisms. The term 'customer' indicates freedom of choice in buying services in a market and intends effective market relationships between buyer and seller. Adopting the "customer" perspective in public administration might cause a re-thinking about the foundations of the public sector's role. The shift towards a practice of treating the citizen as a customer may lead to a real change in the relationship between the citizen and the public sector. There is thus a challenge to develop a system that includes innovation and accountability, but at the same time retains the role of the public sector as a vehicle for a sense of community, equal rights and solidarity.

Traditionally, government institutions have tended to use traditional public administration system which employs rigid bureaucratic norms in service delivery. Today, 
there is a clarion call on the entire public sector to be client-focused and market oriented in service delivery. A new paradigm shift has become necessary because of the changing world economic environment, global pressure for nations to enhance their competitiveness in order to attract foreign investments, increasing expectations of consumers that there will be improvements in service quality and that they will pay economic price devoid of corruption and delays. The New Public Management is the new focus recommended in public service delivery. It is accepted worldwide that the public sector also has consumers who need to be cared for and satisfied. NPM has become a global trend to challenge public bureaus by network-based and marketoriented arrangements (Valkama \& Bailey 2001:55).

Although innovation in the public sector has received increased attention only recently, it does not imply that there has been no innovation being practiced before. In fact, innovation has been tried and tested in the public sector using various models and principles, which were mainly influenced by experiences from the private sector. For instance, new public management was implemented with the core tools and ideas borrowed heavily from the private sector in order to fix the issue of inefficiency in the public sector.

NPM is criticized for undermining public service motivation, learning and trust, and for promoting competition and silo thinking (Aagaard, 2011). However innovation opens up new organizational and managerialist constructions and possibilities. The assumption of the NPM that more managerialism will lead to a more efficient administration cannot be taken for granted. NPM reforms are hierarchical because those with leadership responsibilities are normally considered the drivers of the reforms. At the same time, NPM promotes specialized tasks and undermines collaboration across sectors. The administrative culture need to develop the ability of recognizing all employees as potential drivers of innovation (Christensen and Lægreid, 1999:180-181). While NPM focuses on results and efficiency, bureaucracy seem to point to the input side of the public administration and processes to balance the administration system.

\section{An Assessment of Public Service Innovations in West Africa}

Over the past decade, fundamental changes have been transforming societies all over the world. There has been a significant shift within the field of public administration. Many developing countries, including Africa, are now realizing the need for innovation in 
order to provide customer-focused, cost effective, and updated method to improve public service performance.

The African post-colonial predicament has generated so many epithets that describe the continent. Apart from the notorious "Dark Continent" prevalent in the colonial discourse on Africa, a most recent one in journalistic assessment abridged the African continent into an "Island of Want"... The failure of the African governments and of the post-colonial states in Africa is starkly manifested in the decline and decay of bureaucracy, which represents the existential institutional interstice between the government and the citizens (Utomi; cited in Musa, 2014:1). Africa has mainly, unfortunately, been missing out on benefitting from the diversity of its peoples to innovate for a better future. Emphasis has been put on taking diversity as a problem to be solved rather than a resource to be harness for better performance.

Public service has always been the tool available to West African government for the implementation of developmental goals and objectives. It is seen as a pivot for growth of West African economies. It is responsible for the creation of an appropriate and conducive environment in which all sectors of the economy can perform optimally and it is this catalyst of public service that propelled governments in West Africa to search continuously for better ways to deliver their services. However, there is increasing evidence pointing to the deterioration of the public service's performance in Africa as a whole and West Africa in particular. This notwithstanding, the public service in West Africa is perceived as not being innovative for various reasons such as the nature of services rendered, its regulations and standards, etc. Therefore attention ought to be given to it in determining its level of innovation and innovation practices, otherwise it will affect the activities of other sectors in any economy (Obianyo, 2010:49). It is important that if new ideas in the public service are not developed, how can better facilities that can be used in other sectors of an economy be better provided by the public service?

In West Africa countries, the design and implementation of innovation strategies convey a new vision for the entire public service. It has been suggested that innovation has the potential to transform governance and the relationship between the state, citizens and businesses. Today, innovation is changing the way we work, play, learn and govern. It is generating a new revolution already as significant and far-reaching as those of the past. The context of innovation has changed rapidly in recent years. For many 
years, it has been one of the priority goals of West African governments. Innovation projects were seen as important drivers of development, as they provided the inputs for public service delivery and increased performance.

\section{Nigeria}

Nigeria is a country that has always posed a paradox to the international community in terms of its level of development vis-à-vis its public service performance. Innovation in Nigeria is considered by Obasanjo (2004) as the backbone engine, which will run good governance that will drive social and economic transformation in the public service. The Nigerian government has in the last couple of years taken steps to give the country a sense of direction and harmonize the efforts of the disparate organizations and stakeholders in the development of, and utilization of ICT.

The main innovations in Nigerian public service include:

- tracking corruption through the setting up anti-corruption units in all MDAs directly linked to the Anti-Corruption Agencies such as the Independent Corrupt Practices and Other Related Offences Commission (ICPC) and Economic and Financial Crimes Commission (EFCC);

- $\quad$ the setting up of the Bureau of Public Sector Reforms (BPSR) as the institutional framework for sustaining the reform;

- establishment of public procurement practices

- the opening of the post of Permanent Secretary to both administrative and professional/specialist staff;

- the harmonization and unification of job grading and salary systems through the service;

- $\quad$ the introduction of the merit system as a basis for reward (Adegoroye 2006).

In Nigerian public service, innovation has faced a number of challenges that have limited the scope, speed and quality of service rendered. There is no doubt that there are observable limits to the ability of innovations to solve all economic and social problems. Nevertheless, there is a consensus that public service particularly in the area of innovation need to be improved. If innovation and innovative practices are adopted in 
the public service, costs could be saved, utilization of resources could be more efficient, adjustment for the sustainability of the environment could be improved, etc. These and other demands and expectations of the citizens could be met; either by solving them with existing knowledge or by creating new solutions (Obianyo, 2010:91).

Balogun (1983:8-9) identified resistance to innovative ideas as one of the factors that differentiate the Nigeria public sector from its private sector counterpart in situations where public administration is linked with the public sector while business administration is linked with the private sector. Other factors identified by Balogun which are inextricably linked with 'resistance to innovative ideas' are survival, maintenance of status quo, risk avoidance, mistake avoidance, self-protecting, fear of trouble, fear of the unknown, retroactive. While Maduabum (2014:16) notes that the tendency to resist innovative ideas is higher in public management. It ought to have been 'killed' with the transformations which public sector management in Nigeria had undergone over time.

\section{Ghana}

Ghana was among the first African countries to reform its public sector and establish the necessary legal and regulatory framework to support the growth of the sector. Since 1990, the government of Ghana has liberalized the telecommunications sector with the aim of enabling the private sector to actively participate in the provision of services to increase access and coverage, introduce value-added services and boost consumer access to the state-of-the-art technology (Frempong and Atubra, 2001). Ghana has requested Economic Commission for Africa's support to introduce ICT into the process of reforming the civil service and even to implement innovations to support the governance activities. The main innovations in Ghana civil service include:

- the design of a Civil Service Code of Conduct;

- the development of standards for service delivery and printed brochures by service delivery institutions;

- the introduction of a high flyer scheme in 1996 which enables young officers who are deemed to have the potential to be given specialized training to enable them to maximize their potential and strengthen the capacity of the Civil Service through accelerated promotion if they were able to demonstrate their worth; 
- introduction of customer/client orientation through beneficiary surveys;

- the introduction of performance improvement plans and the signing of performance agreements;

- computerization of personnel records;

- the introduction of the Medium Term Expenditure Framework (MTEF) and the linkage of functional reviews to the implementation of the MTEF; and

- separation of policy formulation from implementation through the creation of executive agencies (Economic Commission for Africa, 2010:54).

There is a great potential for the use of innovations development in Ghana. Unlike some other West African countries, Ghana is fortunate to have developed an ICT policy, which indicates the government's commitment to support ICT programmes in the public sector. What is required now is policy implementation with emphasis on the provision of information to the citizen.

From the above discussion, it can be said that innovation in West Africa are not effective and relevant enough to bridge the information and digital gap. Despite all these, researches have shown that in other parts of the world like Thailand, Malaysia, Singapore, Philippines, South Korea, India and Russia, etc., innovations have been successful through the deployment of ICTs to bridge the information and digital gap of the public service delivery which virtually lead to their development (Cheunwatanna, 1998, and Yusof, 2004). It is therefore imperative for West Africa to re-evaluate their public sector innovation programmes in other to achieve effective and sustainable public service performance.

\section{The Future of Public Service Delivery in West Africa}

While public sector innovations hold great promise in West Africa countries, substantial challenges need to be faced. Many innovation projects failed because of insufficient planning capacity and political instability in the sub-region. In order to overcome these challenges, successful implementation requires matching the right technologies with capable and progressive reformers and government systems.

The public service in West Africa needs public servants who can define and pin-point the bottom line of the public service and pursue its realization. It is imperative to realize 
Transforming Public Service Performance in West Africa through Innovations 93

that within the public service, there is need for foresighted public servants who can discern the horizons of the requirements of the future from the standpoint of today; pragmatic dreamers who realize that development will not be wished. It must be planned and implemented. Such public servants are the ones who will be able to transform West African countries and propel their development through sustained innovations in the nature of services and the way they are delivered equitably to everyone (Kauzya, 2013:8).

Innovation is now seen to be critical to public services' ability to respond effectively to the challenges posed by social and technological change and rising public expectations that come with it. The great demand that public services serve users rather than the providers has meant that most of the efforts to develop innovative practice in the public services have been oriented to issues focused on service delivery. Innovation in the public sector can be a way of rethinking old ideas and practices and find solutions to the new problems. In order to create an innovation culture and work systematically with innovation, politicians and public managers need to understand the potentials and risks of innovation, to rethink organisation structures, and to accommodate organisational values, norms and routines in coherence with innovation practices.

It is suggested that policies that impede innovations in the public sector should be eliminated and replaced by more liberal ones that can stimulate creativity and innovation in the public sector. Innovation should be the criterion for judging high performing public sector organisations, and reward systems should be restructured to reflect such changes. These measures will not only help them innovate, but will also result in improved services to the consumers. Also, the implementation of innovations in West African countries requires sound decisions in developing citizen-adoptable initiatives by adopting 'home-grown' approach or to domesticate the application of innovations. This will help avoid experimentation and reduce the risk of failure of innovation due to the low adoption rate of the initiatives.

West African countries need to adopt a holistic and comprehensive approach, with vision and strategy to overcome the barriers and challenges for change. Integrate public sector innovation with other development strategies and policies to ensure a broad base diffusion.

Public sector organizations must first grow to be conversant with its strategies on innovation and build up the required integration. The focus on innovation in a public 
sector context may also improve our overall understanding of innovation, irrespective of sectoral foundation. In the same way as studies of innovation in services have brought about a focus on non-technological innovations, which later have also been applied to the private sector, an expansion of innovation studies to also comprise the public sector can perhaps help shed new light on innovation in the public sector in West Africa in particular and Africa in general.

\section{Conclusion}

It is obvious that in this $21^{\text {st }}$ century, innovation is the theme of public administration. This is because it brings continual change to public organizations. Public sector innovation is increasingly regarded as a central factor to sustain a high level of public services for both citizens and businesses. Therefore public sector should not be treated as a static framework for innovation in the private sector, but rather as a co-evolving actor along innovation in the private sector. Furthermore, parallel to innovation in the private sector, innovation in the public sector should neither be seen independent from the underlying incentive structures that structure behaviour, nor from their wider systemic context. The vast literature on innovation systems has largely tended to ignore the role the public sector plays in processes of innovation.

Innovations in the public sector guarantee survival and improve performance in public service delivery. Thus, any state that is desirous of such growth, should invest heavily on research and development as well as training activities which have been identified as fast sources of innovation and acquisition of innovative ideas. The public sector innovation and its impact on the society have been experienced all over the world. It has undoubtedly become the determinant of progress of nations, communities and individuals.

The study has shown that public sector innovation in West Africa is best explained by citizens' perceptions of 'responsiveness 'and by 'leadership and vision'. The more responsive the public sector are in service delivery, the better leadership and vision they demonstrate, the higher the perceived level of innovation in these systems. 


\section{Suggestions for future research}

Innovation in the public sector in West Africa is an under-researched area. The very fact that we used two countries in West Africa is not adequate as an interpretive lens to study innovations and its effect on public service performance. We specifically chose to use these two countries because we recognize the fact that these countries play significant roles in the development of West Africa sub-region as a whole.

Due to the qualitative nature of this study, it is necessary that further academic research based on empirical data be carried out in order to understand the actual implementation patterns, the challenges and provide more concrete solutions to effective implementation of innovation in public services in West Africa. It is also germane that the cultural barrier to innovations and how it can be managed with the cultural believes and practice in Africa as a whole and West Africa in particular.

\section{List of References}

- Aagard, P. (2011). Organisational Ambidexterity: How to be both Innovative and efficient in the Public Sector. CLIPS Working Paper No. 5. Roskilde University.

- Adamolekun, L. (2002). Africa's Evolving Career Civil Service System: Three Challenges State Continuity, Efficient Service Delivery and Accountability. International Review of Administrative Sciences. 68: 373-387.

- Adegoroye, G. (2006). Public Service Reform for Sustainable Development: The Nigerian Experience. Keynote Address at the Commonwealth Advanced Seminar, Wellinton, New Zealand, 20 February -3 March

- Adu-Gyamfi, O. (2005). Introduction to Public Sector Administration in Ghana. Kumasi: University Printing Press.

- Albury, D. (2005). Fostering Innovation in Public Services. Public Money and Management. 25:51-56

- Arfeen, R.I and Khan, N. (2013). Public Sector Innovation: Case study of e-government projects in Pakistan. Manchester Institute of Innovation Research Manchester Business School, University of Manchester United Kingdom 
- Babie, E. (2004). The Practice of Social Research (10 ed.). Belmont: CA, USA: Wadsworth.

- Balogun, M.J. (1983). Public Administration in Nigeria: A Developmental Approach. London: The McMillan Press Ltd

- Bland, T., Bruk, B., Kim, D. and Lee, K. (2010). Enhancing Public Sector Innovation Examining the Network-Innovation Relationship. The Innovation Journal: The Public Sector Innovation Journal. 15(3):1-17.

- Blayse, A.M. and Manley, K. (2004). Key Influences on Construction Innovation, 4(3):1-12.

- Bloch, C; Bugge, M and Slipersaeter, S. (2010). Measuring Innovation in the Public Sector Key Issues and Concepts. Denmark: Danish Centre for Studies in Research and Research Policy (CFA), University of Aarhus.

- Breen, J. (2000, October 1). At the Dawn of Egovernment: The Citizens as Customers. Government Financial Review.

- Cheunwattana, A. (1998). Information for Rural Development: A Multiple Case Study of Library and Information Services to the Rural Communities in Thailand. (PhD Thesis). University of Indiana.

- Christensen, T. and Lægreid, P. (1999). New Public Management: Design, Resistance or Transformation? A Study of How Modern Reforms Are Received in a Civil Service System Public Productivity and Management Review. 23(2):169-193.

- Cohen, S., Eimicke, W., \& Heikkila, T. (2008). The Effective Public Manager: Achieving Success in a Changing Government. New York: John Wiley and Sons.

- Cunningham, P and Karakasidou, P. (2009). Innovation in the Public Sector. Policy Brief No 2. Manchester Institute of Innovation Research. University of Manchester

- Damanpour, F and Gopalakrishnan, S. (2001). The dynamics of the adoption of product and process innovations in organizations. Journal of Management Studies. 38:45-65

- Donahue, J.D. (2005). Dynamics of Diffusion: Conceptions of American Federalism and Public-Sector Innovation. From <httpwww.innovations.harvard.edu/cache/documents/6771.pdf.> (Retrieved on October 22, 2014).

- Economic Commission for Africa. (2010). Innovations and Best Practices in Public Sector Reforms: The Case of Civil Service in Ghana, Kenya, Nigeria and South Africa. 
- Ekpo, M.U. (1979). Bureaucratic Corruption in Sub-Saharan Africa. Washington: University Press of America Washington, D.C.

- Eme, O.I.I \& Emeh, I.E.J. (2012). Bureaucracy and Rural Development; the Role of Public Administration in National Development: The Nigerian Perspective. Global Journal of Management and Business Research. 12(4): 18-40

- Eran, V; Aviv, S; Nitza S and Ayalla R. (2008). Public Sector Innovation for Europe: A Multinational Eight-Country Exploration of Citizens' Perspectives. Public Administration. 86(2):307-329.

- European Commission (2013). Overview of European Commission initiatives related to Public Sector Innovation. Directorate C: Research and Innovation, C.1. Innovation Policy.

- Fatile, J.O and Adejuwon, K.D. (2010). Professionalism and Civil Service Reforms in Nigeria: An Appraisal. In Terhemba, W and Talla, N.S. (eds). Governance and Economic Development in the Fourth Republic. Lapai: Department of History and Archaeology, IBB University

- Frempong, G. K., \& Atubra, W. H. (2001). Liberalisation of TELECOMS: The Ghanaian Experience. Telecommunications Policy, 25(3):197-210.

- Hargadon, A and Sutton, R. (2000). Building an Innovation Factory. Harvard Business Review

- Hartley, J. (2005). Innovation in Governance and Public Services: Past and Present. Public Money and Management. 25:27-34

- Heeks, R. (2002). E-government in Africa: Promise and Practice. Manchester, UK: Institute for Development Policy and Management, University of Manchester.

- Hernon, P., \& McClure, C. (1988). Public Access to Government Information: Issues. New Jersey: Trends and Strategies.

- Hicks, H.G and Gullet, R.C. (1982). Organizations: Theory and Behaviour. Tokyo: McGrawHill Kogakusha Ltd.

- Hoque, Z. (2008). Measuring and Reporting Public Sector Outputs/Outcomes: Exploratory evidence from Australia. International Journal of Public Sector Management. 21(5):468-493.

- IDeA Knowledge. (2005), Innovation in Public Services: Literature Review. Retrieved: October 15, 2014 from http://www.idea.gov.uk/idk/aio/1118552

- Ikelegbe, A. (2005). Public Policy Analysis. Benin-City: Imprint Services 
- Kamarck, E.C. (2004). Government Innovation around the World. Ash Institute for Democratic Governance and Innovation, John F. Kennedy School of Government, Harvard University, November 2004

- Kauzya, J. (2013). Professionalising Human Resource Management in the Public Service in Africa. New York: United Nations Public Administration Programme.

- Koch, P. \& J. Hauknes. (2005). Innovation in the Public Sector. Report no D20. Public project under the EU 5th Framework Programme. Oslo: NIFU STEP.

- Kwame, A; Alex, O and Emmanuel, Y. (2013). Enhancing Public Sector Productivity in Ghana: A Qualitative Study. Journal of Public Administration and Governance. 3(3):22-34

- Lundvall, B.A. (1992). National Systems of Innovation: Towards a Theory of Innovation and Interactive Learning. London: Pinter.

- Maduabum, C.P. (2014). Bureaucracy: A Tool for Scuttling Application of Innovative Ideas in the Nigerian Public Service. International Journal of Public Administration and Management Research. 2(2):11-21

- Markus, M.B; Johan, H; Carter, B. and Stig, S. (nd). The Public Sector in Innovation Systems. Output from the joint Nordic research project 'Measuring Public Innovation in Nordic Countries: Toward a common statistical approach': Module 1: Examining the heterogeneity of public sector.

- Maron A. (2008): Innovation in the Construction Industry.

- Modibo O.T. (1978). Law in Aid of Development. Accra: Ghana Publishing Corporation.

- Moore, H.M., Sparrow, M., Spelman, W. (1997). Innovation in Policing: From Production lines to Jobs Shops. In Altshuler, A.A., Behn, R.D. (eds). Innovation in American Government. Washington D.C: The Brookings Institution Press.

- Mulgan, G. \& Albury, D. (2003). Innovations in the Public Sector. London: London Cabinet Office.

- Mulgan, G. (2007). Ready or Not? Taking Innovation in the Public Sector Seriously. NESTA Provocation 03.

- Musa, S.I. (2014). The Collapse of Probity and Good Governance in Nigeria: The Bureaucracy Discharged But Not Acquitted. Global Journal of Political Science and Administration. 2(4):1-11 
Transforming Public Service Performance in West Africa through Innovations 99

- Mytelka, L.K. (2000). Local systems of innovation in a globalised world economy. Industry and Innovation. $7(1): 15-32$

- Newman, J. (2001). Modernizing Governance: New Labour, Policy and Society. London: Sage.

- Obianyo, A.I. (2010). Innovation Processes and Practices in Construction Industry In Anambra State Of Nigeria. A Thesis Submitted In Partial Fulfillment For The Award Of Master of Science (M.Sc.) in Construction Management. November, 2010.

- OECD/Eurostat. (2005). The Oslo Manual. Paris- France: OECD.

- Okafor E.E. (2005). Public Bureaucracy and development in Nigeria: A critical Overview of Impediments to Public Service Delivery http.//www.codesria.org/links/Publications/bulletin3_05/Okafor. accessed on October 22, 2014.

- Okibo, B.W and Shikanda, E.W. (2013). Effects of Organizational Culture on Innovation in Services Industry: A Case Study of Postal Corporation of Kenya. European Journal of Business and Management. 3(3):66-84

- Owusu, F. (2006). Differences in the Performance of Public Organizations in Ghana: Implications for Public Sector Reform Policy. Development Policy Review. 24(6):693-705.

- Oyediran, O. (2007). Introduction to Political Science. Ibadan: Oyediran Consult International

- Oyelaran-Oyeyinka, R.N.I. (2006). Government and Bureaucracy: Leadership in Nigeria's Public Service. The case of the Lagos State Civil Service, 1967-2005. Universitaire Pers Maastricht.

- Ozohu-Suleiman, A. (2010). Public Administration and the Collapse of Probity and Good Governance in Nigeria: Impact of the Political Superstructure. Paper delivered at a National Conference on 50 years of Public Administration in Nigeria. Jointly organized by the Department of Public Administration, University of Abuja and Nassarawa State University, July 2011.

- Peter, S. (1997). Administrative Theories and Politics, 2nd Edition. London: George Allen \& Unwin.

- Rogers, E.M. (1983). Diffusion of Innovation. New York: The Free Press.

- Sakyi, E.K. (2008). Challenges to the implementation of civil service reform in sub-Saharan African countries: Reflections from Ghana. Legon Journal of International Affairs, 53-87. 
- Seifert, J. W. (2003). A Primer on E-government: Sectors, Stages, Opportunities, and Challenges of Online Governance. Congressional Research Service. The Library of Congress

- Slaughter, E.S. (1988). Models of Construction Innovation; Journal of Construction Engineering and Management. 32-226.

- Sørensen, E. and Torfing, J. (2012). Introduction: Collaborative Innovation in the Public Sector. The Innovation Journal: The Public Sector Innovation Journal. 17(1):1-14.

- Thompson, V.A. (1961). Modern Organization. New York: Knopf.

- Uhunmwuangho, S.O and Osemeke, M. (2010). The Civil Service and Effective Service Delivery in Nigeria: Some Desirable Developments. African Journal of Stability and Development. 4(1):24-39

- Valkama, P, and Bailey, S.J. (2001). Vouchers as an Alternative Public Service Funding System. Public Policy and Administration. 16(1):32-58.

- Walker, R.M. (2006). Innovation Type and Diffusion: An Empirical Analysis of Local Government. Public Administration. 84(2):311-335.

- World Bank. (1999). The World Bank Annual Report 1999. World Bank: Washington, DC

- World Bank. (2008). Public Sector Reform: What Works and Why? World Bank: Washington, DC.

- Yusof, S.M. (2004) Universal Service Provision (USP) for Rural Libraries in Malaysia. CDLAO News Letter, 50.

\section{AUTHOR'S CONTACT}

AWOSIKA, Felix Olanrewaju

Dept of Political Science

University of Lagos

Email: awofelix2014@gmail.com 